\title{
MORPHOLOGICAL CHARACTERIZATION VIA LIGHT AND ELECTRON MICROSCOPY OF ATLANTIC JACKKNIFE CLAM (ENSIS DIRECTUS) HEMOCYTES
}

\author{
Brian M. Preziosi ${ }^{\S}$ and Timothy J. Bowden \\ School of Food and Agriculture, Aquaculture Research Institute, University of Maine, Hitchner \\ Hall, Orono, ME 04469, USA
}

The Atlantic jackknife clam, Ensis directus, is currently being researched as a potential species for aquaculture operations in Maine. The goals of this study were to describe the hemocytes of this species for the first time, provide a morphological classification scheme, and acquire hemocyte counts for healthy E. directus in the winter. We viewed hemocytes under light microscopy (using Hemacolor, neutral red, and Pappenheim's panoptical stains) as well as transmission electron microscopy (TEM). The 2 main types of hemocytes found were granulocytes and hyalinocytes (agranular cells). The granulocytes were subdivided into large and small granulocytes while the hyalinocytes were subdivided into large and small hyalinocytes. The large hemocytes had both a larger diameter and smaller nucleus to cell diameter ratio than their smaller counterparts. Using TEM, granulocytes were found to contain many electron lucent and electron dense granules of various sizes. The granules took up the neutral red stain, which indicated they had low-pH contents. Hyalinocytes had few of these granules relative to granulocytes. Large hyalinocytes had both various organelles and large vesicles in their abundant cytoplasm while small hyalinocytes had little room for organelles in their scant cytoplasm. Total hemocyte counts averaged 1.96 $\mathrm{x} 10^{6}$ cells $\mathrm{mL}^{-1}$ while differential hemocyte counts revealed that granulocytes dominate the hemocyte population (over 75\%). The results of this study provide a starting point for future studies on E. directus immune function.

\section{KEYWORDS}

Ensis directus; razor clams; hemocytes; transmission electron microscopy; morphology

$\S$ corresponding author's email: brian.preziosi@maine.edu 